\title{
Surgical treatment of ruptures of the Achilles tendon: a review of long-term results*
}

\author{
M. Krueger-Franke, C. H. Siebert ${ }^{\dagger}$, S. Scherzer \\ Staaliche Orthopaedische Klinik München, Harlachinger Str. 51, 81547 Munich and ${ }^{\dagger}$ Klinik und Poliklinik für \\ Unfallchirurgie, Sigmund Freud Str. 25, 5300 Bonn 1, Germany
}

\begin{abstract}
The rupture of the Achilles tendon is frequently sportsrelated. In the time from 1 January, 1978 until 31 December, 1988, we treated 358 men and 54 women with such an injury at the Staatliche Orthopaedische Klinik in Munich. The average age of these patients was 43 years. The site of the rupture was generally located between $3-5 \mathrm{~cm}$ proximal of the distal insertion of the tendon. In the follow-up examination of 122 patients with surgical treatment of tendo calcaneus ruptures $85 \%$ showed 'good' to 'very good' subjective results. Of the operated patients $97 \%$ would choose the same treatment under similar circumstances. The isokinetic studies demonstrated a loss of static and dynamic strength in plantar flexion of the ankle joint of $9.1 \%$, and $16.7 \%$ respectively, when compared to the healthy contralateral side. The ultrasound examination revealed a thickening of the tendon and of the dorsal paratenon with changes in the internal structure of the injured Achilles tendon. In spite of these favourable results, the high complication rate of $15.1 \%$ shows the need for new and extensive studies regarding the various alternative treatment forms, such as functional, nonoperative options, to finally resolve the debate about the optimal treatment of Achilles tendon ruptures.
\end{abstract}

Keywords: achilles tendon rupture, sports injury, tendon suture

Ruptures of the Achilles tendon have been described since antiquity and have in the past been associated with near certain death. This belief is mirrored in Greek mythology: Achilles died after suffering an injury of the calcaneal tendon through an arrow released by the goddess Apollo.

The discussion regarding the proper treatment of this injury goes back as far as the first scientific descriptions. In central Europe, the surgical treatment of an Achilles tendon rupture was first described in the 19th century, although the conservative methods were preferred at the time ${ }^{1}$. In the 20th century, operative treatment has become the standard therapy for such ruptures. In later years, Arndt ${ }^{2}$

*No benefits in any form have been received or will be received from a commercial party related directly or indirectly to the subject of this article. No funds were received in support of this study.

Address for correspondence: Dr M. Krueger-Franke, Staatliche Orthopaedische Klinik, Harlachinger Str. 51, 81547 Muenchen, Germany defined the indication for surgical intervention as follows: 'Generally, it should be carried out by every substantiated suspicion of an Achilles tendon rupture - partial or complete'.

Since the publication of data regarding the nonoperative-functional treatment of this injury by Thermann and Zwipp ${ }^{3-5}$, a renewed debate over the proper form of treatment has erupted. This controversy has moved us to critically analyse our results of surgically treated Achilles tendon ruptures.

\section{Materials and methods}

From 1 January, 1978 to 31 December, 1988, 451 operations on the Achilles tendon, primary as well secondary procedures, were carried out on 426 patients at the Staatliche Orthopaedische Klinik in Munich. 420 primary ruptures were surgically managed in 412 individuals. The patient group consisted of 54 women and 358 men with an average age of 43.3 years (range $17-87$ years).

Of these patients, 122 were available for follow-up examinations, on average 5.9 years (range 2.2-12.3 years) after the original injury. The operative procedure was carried out as described by Kirchmayr in $1917^{6}$ utilizing non-resorbable suture material in all instances. This group consisted of 15 women and 107 men with an average age of 41.1 years (range 22.0-74.0 years).

Postoperatively, the affected extremity was immobilized for 2 weeks in an long-leg cast in $30^{\circ}$ of plantar flexion in the ankle, which was then reduced to $15^{\circ}$ for the second two week period. For the final 2 weeks of a 6 week immobilization period a short-leg walking cast in neutral position was applied. For the following 3 months a heel elevation of $1.5 \mathrm{~cm}$ was prescribed. A programme of physical therapy was only necessary in isolated instances.

Of the 122 patients available for follow-up examinations, 50 also completed a questionnaire concerning the subjective results. An ultrasound examination using the Siemens Sonoline ${ }^{\oplus}$ model with a $5.0 \mathrm{Mhz}$ linear transducer was carried out on 71 patients (9 women, 62 men; average age 44 years). The examination was performed with the ankle in a neutral position. The classification of the internal structure of the Achilles tendon was carried out using a modification of the Thermann model $^{3}$ and the 
Surgical treatment of ruptures of the Achilles tendon: M. Krueger-Franke et al.

Table 1. Classification of changes in ultrasound image patterns in the operated calcaneal tendon (modification of Ref. 3 )

\begin{tabular}{lcc}
\hline Description & Definition & Thermann equivalent \\
\hline $\begin{array}{l}\text { Light, long, parallel internal } \\
\text { echos, tightly packed }\end{array}$ & 0 & $1^{\circ}$ \\
$\begin{array}{l}\text { Thinner, shorter spread } \\
\text { internal echos }\end{array}$ & - & $2^{\circ}$ \\
$\begin{array}{l}\text { Isolated organized internal } \\
\text { echos, dilute image }\end{array}$ & -- & $3^{\circ}$ \\
$\begin{array}{l}\text { Shorter, tightly packed } \\
\text { internal echos } \\
\text { Isolated parallel internal } \\
\text { echos, intense image }\end{array}$ & + & \\
\hline
\end{tabular}

saggital circumference of the paratenon and tendon was compared to the contralateral side.

Ninety patients (10 women, 80 men; average age 42.5 years) took part in an isokinetic analysis in a seated position using the Cybex II dynamometer (Lumex Inc, NY, USA). Measurements of dorsalextension/plantarflexion were carried out at speeds of $30 \%$ to determine static strength and at $120 \%$ for dynamic strength. The loss of strength following 10 cycles at $120 \%$ was used as an indicator for endurance.

\section{Results}

\section{Medical history}

A review of the available medical histories revealed that of the 365 primary Achilles tendon ruptures, 271 cases were classified as sports-related injuries, one as a motor vehicle accident and in 93 instances other causes were described.

The analysis of the intraoperative findings revealed 315 complete ruptures, 22 partial ruptures and four cases in which the tendon tore at the transition into the muscle. In three cases an avulsion fracture at the calcaneal insertion was reported. In a total of 21 operative reports, the rupture was not described in any further detail. The localization of the rupture was clearly defined in 303 reports. On average the rupture site was $4.78 \mathrm{~cm}$ (measured intraoperatively) proximal to the tendon's insertion into the calcaneus (Figure 1).

A review of the 365 medical histories revealed 55 complications, equivalent to a complication rate of $15.1 \%$ (Table 2). The rate of repeat ruptures was

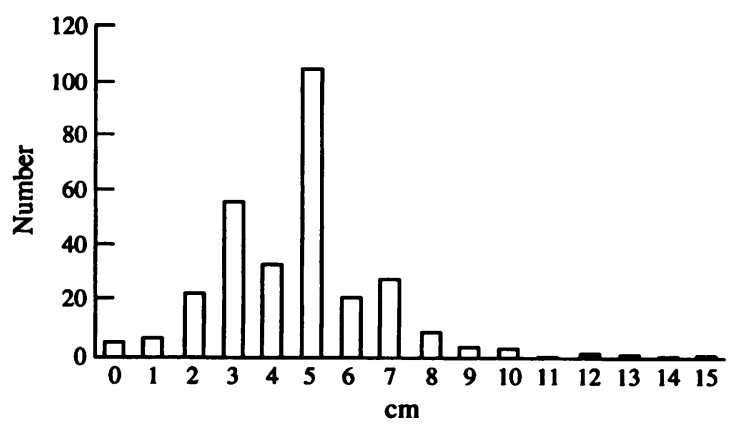

Figure 1. Location of the Achilles tendon rupture (in $\mathrm{cm}$ from the distal insertion) $(n=303)$
Table 2. Distribution of the 55 complications reported following surgical treatment of Achilles tendon ruptures $(n=365)$

\begin{tabular}{lc}
\hline Complication & Number \\
\hline Rerupture & 9 \\
Deep venous thrombosis & 7 \\
Pulmonary emboli & 3 \\
Infection & 13 \\
Secondary wound healing & 9 \\
Dysaesthesias & 14 \\
\hline
\end{tabular}

determined to be $2.5 \%$ and the rate of infection $3.6 \%$. An additional $2.5 \%$ developed problems associated with wound healing without positive microbiology or the need for surgical revision. The complication rate was directly related to the localization of the rupture. The Achilles tendon ruptures that were found to be 10 or more $\mathrm{cm}$ proximal of the calcaneal insertion, developed an infection in $40 \%$ of the cases. The ruptures close to the calcaneus $(2 \mathrm{~cm}$ or less) were found to have a rerupture rate of $6.1 \%$.

\section{Follow-up examination}

Subjective results

The 172 patients available for a subjective analysis of postoperative results were questioned regarding pain at the site of the surgery. Slight pain and discomfort were reported by 47 patients, moderate symptoms by 12 patients, and in three instances significant pain was reported. No symptoms or any discomfort were documented in 110 cases.

The subjective evaluation of the postoperative outcome was classified as 'very good' by 87 patients, as 'good' by 60 , as 'moderate' by 14 , and as 'poor' by five patients. A total of six patients did not respond to this question.

Of the 172 patients who underwent surgical repair of a torn Achilles tendon, 162 would undergo the same treatment under the same circumstances, while two patients would choose non-operative management. In eight instances no response was made.

\section{Clinical results}

The inspection of the Achilles tendon revealed normal scar tissue without signs of inflammation in 117 cases. Two patients developed a keloid and two showed signs of an erythema.

The palpatory examination of the tendo calcaneus revealed a normal finding in 105 cases, in nine patients an obvious induration of the tendon was felt. A tenderness upon palpation was described by eight patients.

On the operated side, a one legged toe rise was carried out without a problem by 109 patients; while eight patients could only perform this test when using both legs simultaneously. Four patients were unable to do toe rises on the operated side.

The measurement of calf circumference at $15 \mathrm{~cm}$ below the medial knee joint showed an average loss of $1.4 \mathrm{~cm}$ on the operated side. The determination of the range of motion in the ankle including the 
comparison to the opposite side was carried out using the neutral zero method of joint motion measurement as advocated by the American Academy of Othopedic Surgeons. These examinations showed normal findings with free range in 101 patients; nine patients had a reduction of plantarflexion of $10^{\circ}$. A reduced dorsalextension of between $5^{\circ}$ and $10^{\circ}$ was documented in five patients; and seven patients developed an equinus of $5^{\circ}$ postoperatively.

\section{Isokinetic results}

The pseudostatic strength tests of plantarflexion carried out at a speed of $30 \%$ revealed an average weakening of the operated side of $6.3 \mathrm{Nm}$ (range $-46.8-57.3 \mathrm{Nm}$ ), while the average strength of the opposite extremity was documented at $77.1 \mathrm{Nm}$. The pseudostatic strength loss turned out to be $9.1 \%$ of the values found during testing of the healthy side.

The measurement of the dynamic strength during plantarflexion tested at a speed of $120 \%$ s showed a strength loss in operated extremity of an average of $6.9 \mathrm{Nm}$ (range $-14.2-38.0 \mathrm{Nm}$ ). The average strength of the opposite, healthy side was $47.0 \mathrm{Nm}$. An average reduction of maximal strength of the operated side of $16.7 \%$ compared to the opposite side was, therefore, documented.

The endurance testing at $120 \%$ for 10 flexionextension movements in the ankle, comparing both sides, revealed that in 61 out of 80 examinations $(76.3 \%)$ a reduction of, on average, $7.2 \mathrm{Nm}$ (range $-11.5-27.3 \mathrm{Nm}$ ) for the operated extremity was found. In 10 patients the endurance of the injured side was better than, in nine patients equal to, the opposite side.

\section{Ultrasound results}

The ultrasound examination showed no loss of continuity in any of the Achilles tendons. The internal patterns of the surgically treated tendons seen in ultrasonography were inhomogeneous when compared to the opposite side (Figure 2).

The measurement of the sagital circumferences of the tendo calcaneus revealed in the group of 71 patients examined, seven cases of a thinning out of the operated tendon compared to the healthy side, while in 64 instances a thickening of, on average, $0.38 \mathrm{~cm}$ was discovered (Figure 3 ).

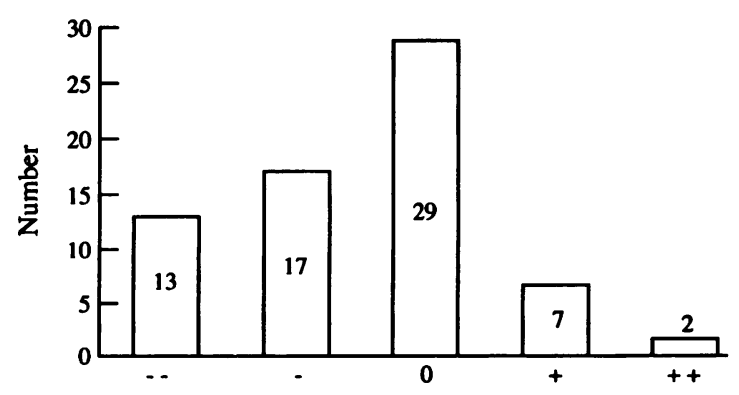

Figure 2. Changes in the ultrasound pattern in the operated tendon, compared to the healthy contralateral side, modified Thermann classification ${ }^{3}(n=55)$

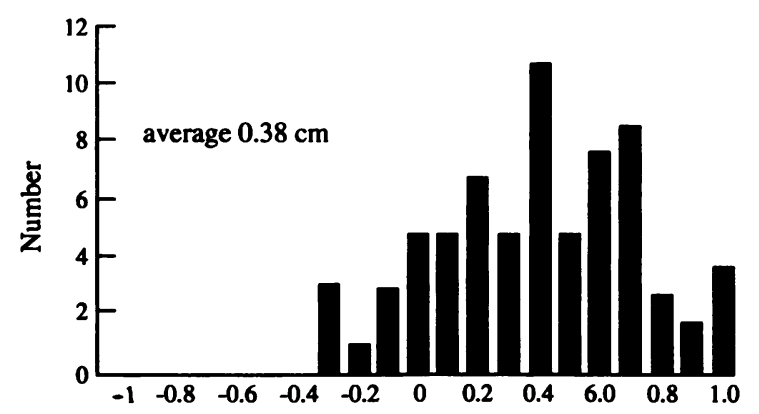

Figure 3. Thickening of the surgically repaired Achilles tendon, shown as sagittal circumference by ultrasonography in a standardized plane $(n=71)$

In 63 patients, the dorsal paratenon also showed a thickening on the operated side when compared to the contralateral side of, on average, $0.1 \mathrm{~cm}$ (range $-0.1-0.3 \mathrm{~cm}$ ).

\section{Discussion}

A review of the literature concerning medical histories combined with the follow-up examinations once again showed that the rupture of the Achilles tendon is often sports-related $d^{3-5,7-10}$.

A partial tear of the tendon, an entity whose existence has frequently been denied ${ }^{11}$, had an occurrence rate of $6.1 \%$ in our patient group. These results are comparable to those published in other studies $^{7,8}$ and prove the existence of partial Achilles tendon tears.

The location of the tendon rupture found in this study is comparable to that reported by other

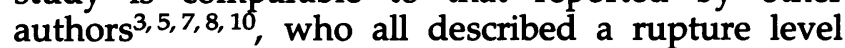
between $3-5 \mathrm{~cm}$ proximal of the distal insertion. The hypothesis that this may be due to the poorer circulation at this level can, in light of newer studies $^{12,13}$, no longer be upheld ${ }^{14}$.

In this study, the reported complication rate of $15.1 \%$ seems relatively high, although the repeat rupture rate of $2.5 \%$, the rate of infection of $3.6 \%$, as well as the rate of secondary wound healing of $2.5 \%$ are comparable to those described in other studies ${ }^{5,7}$. The high infection rate seen in the atypical, high, proximal tendon ruptures, as previously described by Zwipp ${ }^{5}$, is possibly related to the higher intraoperative trauma combined with the larger tissue area affected by the injury.

The increased rate of reruptures seen in tears of the more distal tendon, which is associated with a short distal base, seems to be related to the difficulties in suturing technique. In such cases, a primary augmentation with the help of the plantaris tendon or a transosseous refixation seems advisable.

The large number of dysaesthesias found in the vicinity of the scar $(3.9 \%)$ in our study are not mentioned in the other studies and cannot be explained anatomically by the standardized, posteromedial skin incision used at our hospital. Such dysaesthesias are possibly assessed in a different manner by other groups. 
The summation of the clinical, ultrasound and isokinetic examinations permits the conclusion that the primary reconstruction of the torn tendo calcaneus without augmentation, as is standard treatment in our hospital, does not lead to a restitutio ad integrum of the tendon. In addition to the obvious muscle atrophy of $1.4 \mathrm{~cm}$ on the operated side, changes in the internal structure of the tendon, as seen in ultrasonography, have been documented. A reduction in static, as well as dynamic, strength in plantarflexion of $9.1 \%, 16.7 \%$ respectively, compared to the healthy contralateral side was also measured.

The ultrasound examination of our patients did not show the internal structure changes described by Thermann ${ }^{3}$ but rather showed an inhomogeneous distribution of a whole spectrum of sonographic changes (Figures 4 and 5). Our results do not show defined, ultrasound controllable, changes equivalent to the healing of a ruptured Achilles tendon. The large number of patients with scarlike thickening of the tendon in the injured area (Figures 6 and 7), does not influence the clinical or isokinetic results.

The regimens utilizing strict immobilization do not have the advantages achieved with conservativefunctional treatment (lower rate of deep venous thrombosis, less muscle atrophy, quicker rehabilitation), whilst also not offering the positive sides of operative therapy (exact adaptation of the torn tendon, proper strength-length relationship of muscletendinous unit). Apart from the reduced rate of infection, the immobilizing treatment combines the negative aspects of both alternative methods.

The central point of debate is the repeat rupture rates associated with the various treatment forms. Various studies of conservatively managed Achilles ruptures have shown reruptures rates of $17.7 \%{ }^{5}$ and have frequently been used by the proponents of surgical treatment to support their viewpoint ${ }^{7,8}$.

In the near future, orthopaedic and trauma surgeons may be forced to reconsider their management of Achilles tendon ruptures, if the long-term follow-up studies of patient groups treated in a conservative-functional manner reveal results that are as promising as those seen in the short-term reviews $^{3,4}$.

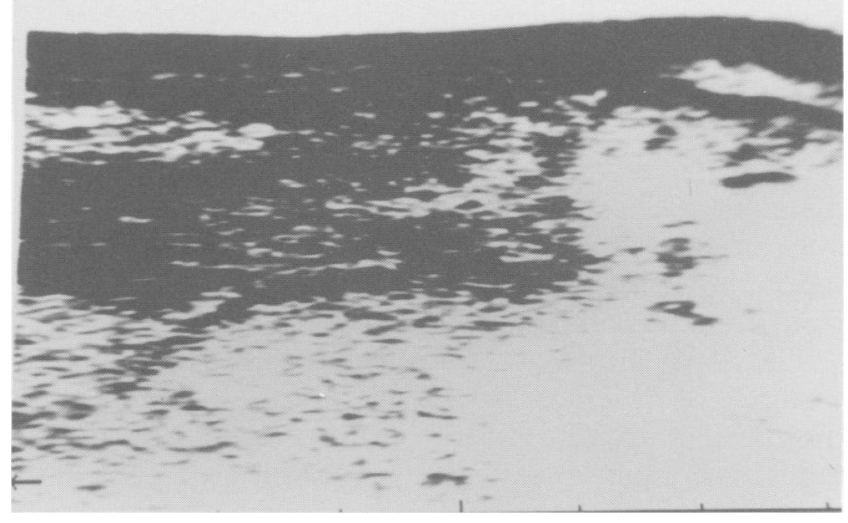

Figure 4. Ultrasound image of surgically repaired tendo calcaneus depicting inhomogeneous internal pattern

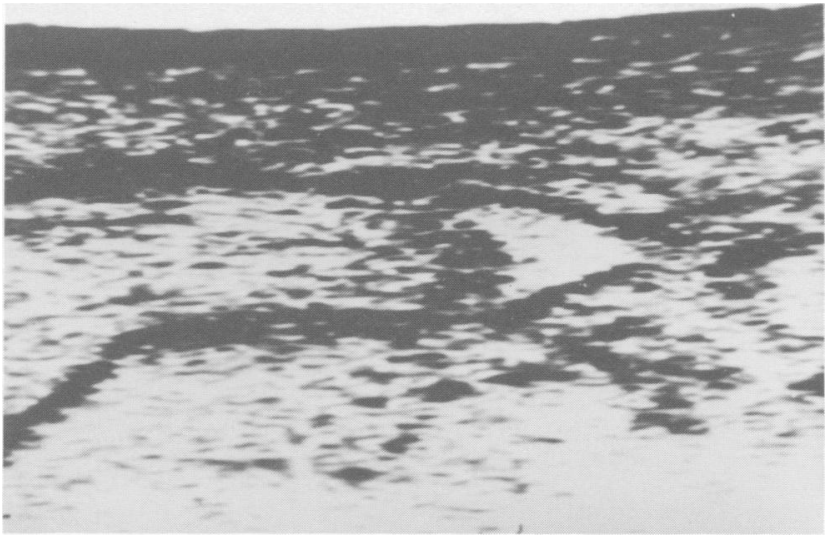

Figure 5. Ultrasound image of surgically repaired tendo calcaneus depicting inhomogeneous internal pattern

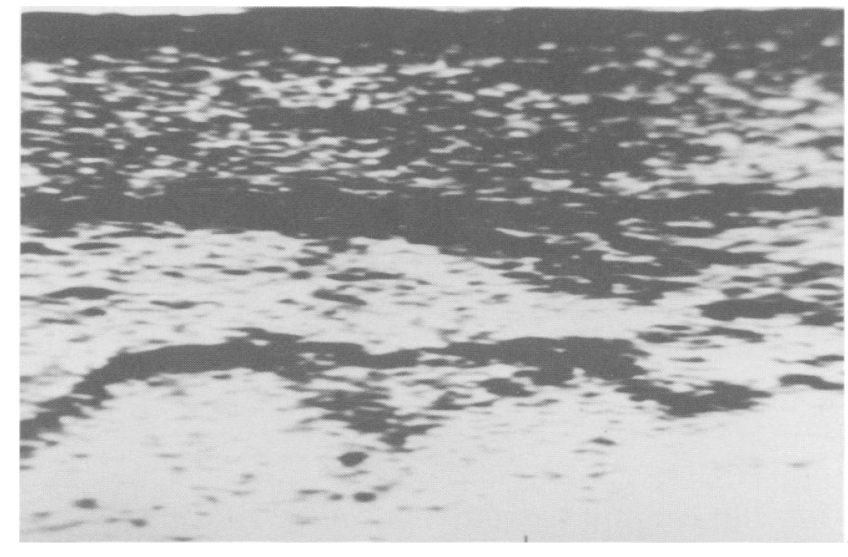

Figure 6. Ultrasound image showing thickening of calcaneal tendon in former rupture zone

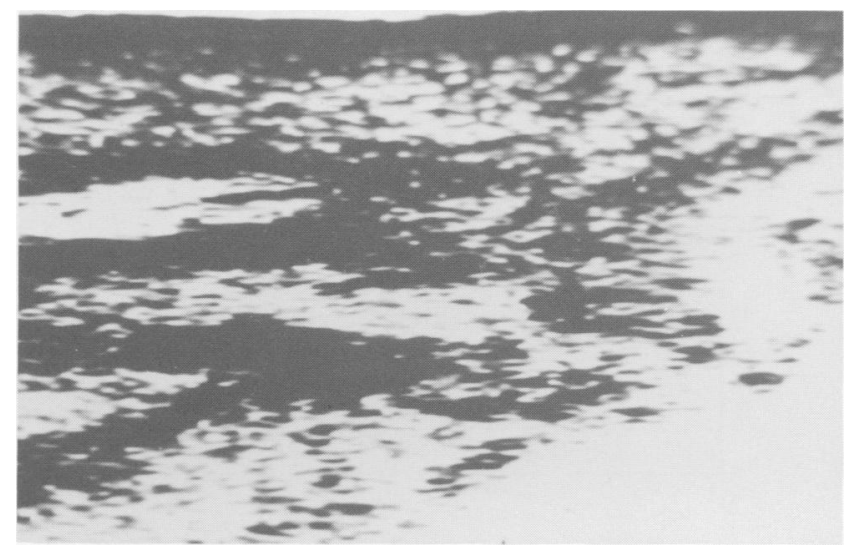

Figure 7. Ultrasound image showing thickening of calcaneal tendon in former rupture zone 


\section{References}

1 Hurd A. Gesammelte Medizin. 10. Jahrgang, Bannd 2, Berlin, Germany; 1876.

2 Arndt K-H. Achillessehnenruptur und Sport. Leipzig, Germany: Johann Ambrosius Barth Verlag, 1976.

3 Thermann H, Zwipp H, Milbradt H, Reimer P. Die Ultraschallsonographie in der Diagnostik und Verlaufskontrolle der Achillessehnenruptur. Unfallchirurg 1989; 92: 266.

4 Zwipp H, Thermann H, Suedkamp N, Tscherne H, Milbradt $H$, Reimer $P$, Heintz P. Ein Innovatives Konzept zur primärfunktionellen Behandlung der Achillessehnenruptur. Sportverl Sportschaden 1990; 4: 29.

5 Zwipp H, Suedkamp N, Thermann H, Samek N. Die Achillessehnenruptur - 10 Jahresspätergebnisse nach operativer Behandlung. Eine retrospektive Studie. Unfallchirurg 1989; 92: 55.

6 Kirchmayr L. Zur Technik der Sehnennaht. Zbl Chir 1917; 40: 906.

7 Burchhardt $H$, Krebs $U$, Schlemminger R, Stankovic $P$.
Achillessehnenruptur. Z Orthop 1992; 130: 109.

8 Mayer M, Donner U, Strosche H. Die operative Behandlung der frischen subkutanen Achillessehnenruptur und deren Behandlungsergebnis. Akt Traumatol 1989; 13: 111.

9 Suckert K, Benedetto KP, Vogel A. Entwicklung der Achillessehnenruptur im Skisport Akt Traumatol 1983; 13: 111.

10 Viernstein K, Galli H. Achillessehnenrupturen. Wiederherstellungschir Traumatol 1964; 8: 186.

11 Schoenbauer HR. Gibt es unvollständige Risse der Achillessehne? Zbl Chir 80 1955; 12: 471.

12 Carr AJ, Norris SH. The blood supply of the calcaneal tendon. J Bone Joint Surg 1989; 71-B: 100.

13 Lagergren C, Lindholm A. Vascular distribution in the Achilles tendon. Acta Chir Scand 1989; 116: 491.

14 Schmidt-Rohlfing B, Graf J, Schneider U, Niethard FU. The blood supply of the Achilles tendon. Intern Orthopaedics 1992; 16: 29.

15 Wills CA, Washburn S, Caiozzo V, Prietto CA. Achilles tendon rupture. A review of the literature comparing surgical versus non-surgical treatment. Clin Orthop 1986; 207: 156. 